\title{
Physicians knowledge and attitude of opioid availability, accessibility and use in pain management in Bangladesh
}

\author{
Khan $\mathrm{F}^{1}$, Ahmad $\mathrm{N}^{1}$, Iqbal $\mathrm{M}^{2}$, Kamal $\mathrm{AM}^{3}$ \\ ${ }^{1}$ Centre for Palliative Care, Bangabandhu Sheikh Mujib Medical University (BSMMU), Dhaka, ${ }^{2}$ National \\ Institute of Population Research and Training (NIPORT), Dhaka, ${ }^{3}$ Department of Narcotics Control, Dhaka. \\ Email: farzanakhan04@yahoo.com
}

\begin{abstract}
This survey was conducted on 1000 physicians with pain management responsibilities practicing in 47 districts in Bangladesh. The response rate was $58.3 \%$. The physicians had a mean of 21 years in practice. It was notable that $66 \%$ of the physicians had seen cancer patients in the last 12 months and $63 \%$ had seen patients with advanced stage cancer where opioids are considered as the mainstay of treatment. It was discouraging that $85 \%$ of the physicians preferred to prescribe pethidine, when patients needed opioids for severe pain. $53 \%$ of the physicians were not aware of the 'Bangladesh Narcotics law, 1990'. $89 \%$ of the physicians would restrict opioid dosage in pain management to prevent drug tolerance or addiction. Oncology physicians displayed significantly higher knowledge scores. The results demonstrated physicians' poor knowledge, attitude and perceived barriers regarding opioids. Effective education strategies need to be addressed using the study result.
\end{abstract}

\section{Introduction}

Pain is one of the most common reasons for having a medical consultation in primary health care, but $20 \%$ of the pain patients used to suffer from pain for more than 6 months ${ }^{1}$. It is known that moderate to severe pain is experienced by $70-90 \%$ of the patients with advanced cancer and $30-40 \%$ of the cancer patients undergoing definitive treatment ${ }^{2}$. Opioids are essential, safe and effective medicines for the relief of moderate to severe acute and chronic pain ${ }^{3}$. Chronic opioid therapy can be used to treat pain in cancer patients ${ }^{4}$ and carefully selected patients in case of chronic non-cancer pain and pain in $\operatorname{AIDS}^{5}$.

Freedom from pain is a basic human right. According to the World Health Organization (WHO), morphine consumption is an important indicator of a country's situation and progress in cancer pain relief ${ }^{6}$. The previous studies found that one of the major barriers for adequate pain management is significant lack of physician knowledge and education in opioid analgesics ${ }^{\mathbf{7 , 8}}$. In 1999 the International Association for the Study of Pain (IASP) identified an important barrier to pain knowledge that pain was not well integrated into the medical curriculum?. The lack of knowledge may be related to the overall situation of teaching of pain which is known to be an inadequate, unstructured, disorganized and fragmented ${ }^{\mathbf{1 0 , 1 1}}$.

Concern for inadequate medical use of opioids in Bangladesh was raised by the researchers 12 years back $^{12}$. A qualitative study reported the barriers of opioids use in Bangladesh as: inadequate dosing, interrupted drug supply, legal restrictions and unavailability of immediate release morphine ${ }^{\mathbf{1 3}}$. Opioid consumption in Bangladesh in 2012 was only $0.05 \mathrm{mg} / \mathrm{capita}^{\mathbf{1 4}}$. The low consumption indicates that the pain management situation in the country is still miserable.

To get an optimal idea regarding pain management in Bangladesh, we found it essential to understand the knowledge and attitudes of physicians regarding opioid drugs. This is the first of this kind of study in Bangladesh on opioid issue. The objective of the study was to gather pertinent Bangladeshi information to assist health professionals, policy makers and the community in the development of programs to improve the care of patients with moderate to severe pain.

\section{Materials and Methods}

A cross sectional survey was conducted from March 2013 to October 2013 to assess the knowledge and attitude towards opioid use amongst physicians practicing in 47 districts of Bangladesh. Approval of the study was obtained from the Ethical Review Committee of Bangladesh Medical Research Council (BMRC). 1000/One thousand Bangladeshi Physicians with Bangladesh Medical and Dental Council (BMDC) registration were recruited by purposive sampling to reflect a broad range of socio-demographic backgrounds. The study was undertaken jointly by the Centre for Palliative Care (CPC), BSMMU and Department of 
Narcotics Control (DNC), Bangladesh. Data were collected by the DNC team from 47 districts of Bangladesh. Physicians from basic medical sciences who were not expected to prescribe opioids and those who did not have BMDC registration were also excluded from the study.

The prospective participants were provided with an invitation letter signed by the principal investigator to participate in the study, consent form along with participant information sheet explaining the purpose of the study, methodology and promising confidentiality. If they agreed \& signed the consent form they were included in the study. The research team then handed over preset questionnaires to the participants and requested to complete those within one week. The team members then collected the completed forms after one week. Non-respondents were followed-up after the initial one week completion time to encourage participation. All participation was voluntary. The respondents were assured anonymity.

Study Instrument: A 31-item questionnaire was developed by the research committee based on a review of questionnaires used in similar surveys including: A 2010 Survey of Washington physicians $^{8}, 2008$ survey of Georgia physicians ${ }^{15}$, a 2004 Survey of Barriers to Opioid Availability in Italy, a 2000 survey of Taiwan physicians ${ }^{6}$, a 1996 survey of Finland physicians ${ }^{\mathbf{1 6}}$ and guidelines by WHO 2000 in Achieving balance in National opioids control. Items related to specific Bangladesh laws and regulations were included to reflect awareness of physicians regarding narcotics law in Bangladesh.

The questionnaire requested information to measure basic knowledge, prevailing attitudes and perceived barriers in relation to opioids on four themes: (a) Background information with current professional status (7 items); (b) physicians knowledge of opioid prescribing in clinical practice (8 items); (c) attitude towards optimal use \& appropriate prescribing of opioids (4 items); and (d) barriers to the availability, accessibility \& use of opioids (12 items).

The survey instrument consisted of two sections. Section I contained a series of questions on background characteristics of the sample including community size, professional training, current employment, year of medical graduation, number of cancer patients seen in the past 12 months, monthly potent opioid prescriptions (Morphine and Pethidine) and number of patients seen with late stage cancer. Physicians were asked if they or someone they know have ever been investigated in connection with opioid prescription practices.
Section II contained 24 questions with the aim to establishing three scales to measure the knowledge, attitude and perceived barriers of physicians regarding opioids. The knowledge scale consisted of 8 questions, 1 positive and 7 negative. A Likert scale containing five-point response format was utilized. Participants were asked to rate each item on five points of this scale with " $1=$ strongly agree", "2=agree", " $3=$ no opinion", "4=disagree" and "5=strongly disagree". The questions addressed three major areas relevant to desired knowledge for prescribing opioids. These are (1) pain assessment and management with potent opioids; (2) knowledge of opioid pharmacology on dosage, route of use, side effects; and (3) tolerance and addiction issues. There were 4 factual questions for the attitude scale. The factual questions were about concern of attitude when prescribing opioids in specific clinical situations. This section also included a list of 12 questions to identify the barriers in relation to opioids.

Statistical Analysis: Data were analyzed using the statistical package IBM SPSS version 21 for Windows. Responses to the self-administered questionnaires were the main outcome measure. Non-parametric methods were used to describe data for independent samples because all examined variables were categorical and the participants were not randomly sampled. Frequency distributions were reported on all background information. Comparisons of knowledge, attitude and perceived barrier scores among the levels of each demographic and practice variable were conducted.

A Mann-Whitney U-test was used to compare the mean responses between the government and private candidates. In the multivariate analysis, the simultaneous relationship of the multiple correlates to the knowledge and attitude deficits or perceived barriers to prescribe opioids were assessed using a logistic regression model. Statistical significance was set at $p<0.05$.

\section{Results}

Sample Characteristics: From the 47 districts 1000 potentially eligible physicians were contacted. Five hundred eighty three physicians completed the questionnaires. The overall response rate was $58.3 \%$. Table I contains the background information of the respondents. The majority of the physicians were from internal medicine (33\%). Other specialities included gynaecology (16\%), surgery (14\%), anaesthesiology (6\%), oncology $(2 \%)$ and others $(17 \%)$. The respondents were in practice of their profession for a mean of 21 years ( $\pm 9.7 \mathrm{SD})$ (range 1-52 years). Forty percent of the respondents were from Dhaka, the capital of 
Bangladesh, 18\% from Chittagong and rest of the participants $(52 \%)$ were from 47 districts of Bangladesh. Sixty four percent of the participants were working in a community where they usually encounter $>3000$ patients per month. Eighty seven percent of the participants were government employee and $6 \%$ of them were practicing in private hospital.

Among the respondents only $15 \%$ mentioned that they had seen $>50$ cancer patients in the last 12 months of time, whereas $52 \%$ had seen $1-50$ cancer patients in their practice area. Twenty four percent of the physicians did not prescribe any opioid in the last 12 months, whereas $28 \%$ had prescribed at least 1-10 prescriptions of opioid within the last one year. Sixty seven percent of the physicians reported no investigation about their opioid prescribing practices, $10 \%$ knew someone who had been investigated and $23 \%$ did not know regarding the matter.

Table I: General Characteristics of the physicians $(\mathrm{n}=583)$ included in the survey

\begin{tabular}{|c|c|c|}
\hline General Characteristics & $\begin{array}{c}\mathrm{N} \\
(\mathrm{N}=583)\end{array}$ & $\begin{array}{c}\% \text { of } \\
\text { Total } \mathrm{N}\end{array}$ \\
\hline \multicolumn{3}{|l|}{ Year of medical degree/ graduation } \\
\hline $1960-1980$ & 28 & 4.8 \\
\hline $1981-2000$ & 352 & 60.3 \\
\hline $2001+$ & 114 & 19.7 \\
\hline Missing & 90 & 15.2 \\
\hline \multicolumn{3}{|l|}{ Years in Medical Practice } \\
\hline $0-10$ years & 92 & 15.8 \\
\hline 11-19 years & 106 & 18.2 \\
\hline$>19$ years & 50.8 & 59.8 \\
\hline Missing & 88 & 15.1 \\
\hline \multicolumn{3}{|l|}{ Professional Training } \\
\hline Anaesthesiology & 33 & 5.7 \\
\hline Oncology & 12 & 2.1 \\
\hline Gynaecology & 92 & 15.8 \\
\hline Internal Medicine & 192 & 32.9 \\
\hline Surgery & 80 & 13.7 \\
\hline Others & 101 & 17.3 \\
\hline Missing & 73 & 12.5 \\
\hline \multicolumn{3}{|l|}{ Practice Setting } \\
\hline Government/Hospital/Academic Hospital & 509 & 87.3 \\
\hline Private practice/Clinic & 37 & 6.3 \\
\hline Missing & 37 & 6.3 \\
\hline \multicolumn{3}{|l|}{ Patients (All Category) seen per month } \\
\hline$>3000$ & 374 & 64.2 \\
\hline $1000-3000$ & 10 & 1.7 \\
\hline$<1000$ & 13 & 2.2 \\
\hline Missing & 185 & 31.7 \\
\hline \multicolumn{3}{|c|}{ No. of Cancer patients seen in the past 12 months } \\
\hline None & 72 & 12.3 \\
\hline $1-50$ & 303 & 52 \\
\hline$>50$ & 84 & 14.4 \\
\hline Missing & 119 & 20.4 \\
\hline \multicolumn{3}{|l|}{ Patients seen with late stage cancer } \\
\hline None & 60 & 10.3 \\
\hline $1-50$ & 249 & 42.7 \\
\hline$>50$ & 131 & 22.5 \\
\hline Missing & 143 & 24.5 \\
\hline \multicolumn{3}{|l|}{ Opioid prescription last year } \\
\hline None & 138 & 23.7 \\
\hline $1-10$ & 165 & 28.3 \\
\hline$>10$ & 149 & 25.6 \\
\hline Missing & 131 & 22.5 \\
\hline \multicolumn{3}{|l|}{$\begin{array}{l}\text { Investigation due to opioid prescription } \\
\text { (participant or others) }\end{array}$} \\
\hline Yes & 57 & 9.8 \\
\hline No & 392 & 67.2 \\
\hline Don't know (\& others) & 143 & 23 \\
\hline Missing & 123 & 21.1 \\
\hline
\end{tabular}

Distribution of the total knowledge, attitude and perceived barrier of the study physicians in relation to the practice setting are presented by box plot (Fig. 1). Differences in all the three scores among the participants were calculated using a MannWhitney U-test. Table II revealed no significant difference in the total knowledge $(M=241.76$, $\mathrm{n}=449)$, total attitude $(\mathrm{M}=222.74, \mathrm{n}=416)$ and total barrier $(M=229.03, n=430)$ of the government and private physicians.

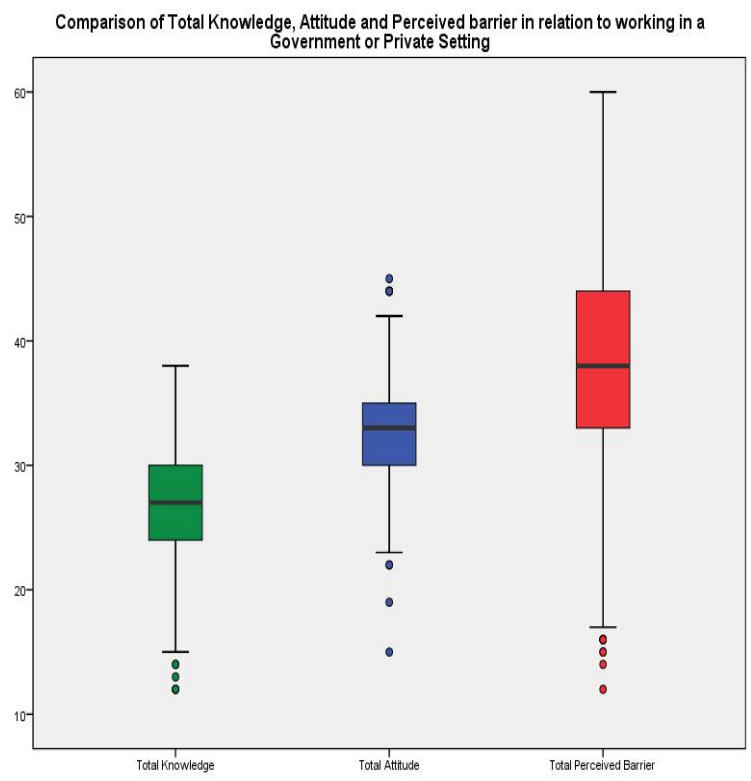

Fig. 1: Comparison of Total knowledge, attitude and perceived Barriers

Table II: Mann-Whitney U-test for comparing differences in total knowledge, attitude \& perceived barriers between government \& private physicians

\begin{tabular}{llll}
\hline Background & \multicolumn{3}{r}{ Ranks } \\
& \multicolumn{1}{c}{$\mathrm{N}$} & Mean Rank & Sum of Ranks \\
\hline Total & $\mathrm{n}=449$ & 241.76 & 108550.00 \\
Knowledge & $\mathrm{P}=32$ & 230.34 & 7371.00 \\
& 481 & & \\
Total & $\mathrm{n}=416$ & 222.74 & 92661.00 \\
Attitude & $\mathrm{P}=28$ & 218.89 & 6129.00 \\
& 444 & 229.03 & 98484.00 \\
Total & $\mathrm{n}=430$ & 258.29 & 8007.00 \\
$\begin{array}{l}\text { Perceived } \\
\text { Barrier }\end{array}$ & $\mathrm{P}=31$ & & \\
\hline
\end{tabular}

Man-Whitney $\mathrm{U}=6843,5723,5819 ; \mathrm{z}=-.450,-.154,-1.182 ;$ sig (2-sided) $(\mathrm{p}=0.01) \mathrm{p}=0.653,0.877,0.237$.

M=Mean Rank

Table III presents the mean total knowledge, attitude and barrier scores by the demogaphic variables. Lower mean scores indicated levels of knowledge, attitudes and barriers. The physicians who had seen more than 50 cancer patients in the last 12 months appeared to have more knowledge than the other groups. 
Table III: Factors Influencing Physician's Knowledge, Attitudes and Barriers Regarding Opioids

\begin{tabular}{|c|c|c|c|}
\hline & $\begin{array}{c}\text { Total } \\
\text { Knowledge } \\
\text { mean (SEM) }\end{array}$ & $\begin{array}{l}\text { Total attitude } \\
\text { mean (SEM) }\end{array}$ & $\begin{array}{l}\text { Total Barrier } \\
\text { Mean (SEM) }\end{array}$ \\
\hline \multicolumn{4}{|l|}{ Years in Medical Practice } \\
\hline $0-10$ years & $28.4(0.49)$ & $25.3(0.55)$ & $38.9(1.0)$ \\
\hline 11-19 years & $26.3(0.45)$ & $26.8(0.51)$ & $37.1(0.96)$ \\
\hline $19+$ years & $26.7(0.32)$ & $26.5(0.36)$ & $38.4(0.68)$ \\
\hline \multicolumn{4}{|l|}{$\begin{array}{l}\text { No. of Cancer patients seen } \\
\text { in the past } 12 \text { months }\end{array}$} \\
\hline None & $27.2(0.66)$ & $26.3(0.74)$ & $40.5(1.4)$ \\
\hline $1-50$ & $27.8(0.28)$ & $25.8(0.32)$ & $30.2(0.6)$ \\
\hline$>50$ & $24.3(0.53)$ & $28.2(0.61)$ & $40.1(1.1)$ \\
\hline \multicolumn{4}{|l|}{ Professional Training } \\
\hline Anaesthesiology & $26.1(0.89)$ & $27.7(0.99)$ & $39.7(1.9)$ \\
\hline Oncology & $21.9(1.4)$ & $30.3(1.6)$ & $43.1(3.1)$ \\
\hline Gynaecology & $28.3(0.55)$ & $25.3(0.62)$ & $37.2(1.2)$ \\
\hline Internal Medicine & $27.2(0.36)$ & $26.3(0.40)$ & $38.9(0.78)$ \\
\hline Surgery & $26.1(0.54)$ & $26.7(0.61)$ & $38.0(1.2)$ \\
\hline Others & $27.2(0.55)$ & $25.7(0.62)$ & $37.6(1.2)$ \\
\hline \multicolumn{4}{|l|}{ Practice Setting } \\
\hline \multicolumn{4}{|l|}{ Government/Hospital/Acad } \\
\hline Private practice/Clinic & $26.7(0.89)$ & $27.1(0.98)$ & $41.9(1.9)$ \\
\hline \multicolumn{4}{|l|}{$\begin{array}{l}\text { Patients seen with late } \\
\text { stage cancer }\end{array}$} \\
\hline None & $26.7(0.81)$ & $26.6(0.89)$ & $41.9(1.7)$ \\
\hline $1-50$ & $27.4(0.34)$ & $25.7(0.37)$ & $37.5(0.69)$ \\
\hline$>50$ & $26.6(0.43)$ & $26.9(0.47)$ & $38.2(0.88)$ \\
\hline \multicolumn{4}{|l|}{$\begin{array}{l}\text { Patients (All Category) } \\
\text { seen per month }\end{array}$} \\
\hline$>3000$ & $27.3(0.26)$ & $26.1(0.29)$ & $37.7(0.55)$ \\
\hline $1000-3000$ & $28.5(1.5)$ & $25.1(1.7)$ & $38.8(3.3)$ \\
\hline$<1000$ & $25.0(1.4)$ & $29.2(1.6)$ & $43.3(3.1)$ \\
\hline \multicolumn{4}{|l|}{ Opioid prescription last year } \\
\hline None & $27.7(0.48)$ & $26.7(0.52)$ & $39.6(0.96)$ \\
\hline $1-10$ & $26.6(0.40)$ & $26.8(0.44)$ & $38.2(0.81)$ \\
\hline$>10$ & $26.9(0.45)$ & $25.4(0.50)$ & $35.8(0.92)$ \\
\hline \multicolumn{4}{|l|}{$\begin{array}{l}\text { Investigation due to opioid } \\
\text { prescription (participant or } \\
\text { others) }\end{array}$} \\
\hline Yes & $27.7(0.48)$ & $26.7(0.52)$ & $39.6(0.96)$ \\
\hline No & $26.6(0.40)$ & $26.8(0.44)$ & $38.2(0.81)$ \\
\hline Don't know (\& others) & $26.9(0.45)$ & $25.3(0.50)$ & $35.8(0.92)$ \\
\hline
\end{tabular}

Knowledge toward opioid prescribing: The mean (SD) total knowledge score was 2.55 (SD, 0.53; range, 1.50-4.75) for this scale. The possible range of score was 1-5. Table IV lists the responses of physicians to knowledge items about opioid prescribing. The majority of the physicians showed inadequate knowledge regarding opioid analgesic prescription. The observed value for each score was plotted against the expected value from the normal distribution. The reasonably straight line suggested a normal distribution.

Eighty percent of the physicians preferred pethidine over Morphine to treat severe pain. Fifty seven percent of the practicing physicians had a misconception that pethidine causes less harmful effects (such as tolerance, addiction, or side effects) amongst the opioids. Similarly $84 \%$ of them had wrong perception about drug tolerance and addiction. Interestingly $39 \%$ agreed that respiratory depression is not a very severe side effect. Almost half $(45 \%)$ of the participants either do not know or hesitant to increase the dose of strong opioids 4 hourly or as needed. Thirty three percent of the respondents think that parenteral administration is more efficacious than that of oral, in case of chronic pain management and in contrast to that $32 \%$ disagreed with the statement. $35 \%$ of the respondents believed that oral administration of morphine induce more nausea \& vomiting than parenteral administration.

Table IV: Physicians'Knowledge Toward Opioid Prescribing

\begin{tabular}{|c|c|c|c|c|c|}
\hline Items & $\begin{array}{l}\text { Strongly } \\
\text { agree }\end{array}$ & Agree & No opinion & Disagree & $\begin{array}{r}\text { Stronly } \\
\text { disagree }\end{array}$ \\
\hline $\begin{array}{l}\text { 1. When patients need potent opioids for severe acute pain (for exam: after } \\
\text { surgery, labour pain), I would prescribe Pethidine rather than morphine. }\end{array}$ & $227(38.9)$ & $239(41)$ & $31(5.3)$ & $40(6.9)$ & $12(2.1)$ \\
\hline $\begin{array}{l}\text { 2. The opioid dosage patients receive should be much lower than the } \\
\text { required dosage so that we avoid drug tolerance. }\end{array}$ & $54(9.3)$ & $203(34.8)$ & $71(12.2)$ & $182(31.2)$ & $34(5.8)$ \\
\hline $\begin{array}{l}\text { 3. Pethidine causes less harmful effects (such as tolerance, addiction, or } \\
\text { side effect) in long-term opioid use. }\end{array}$ & $67(11.5)$ & $196(33.6)$ & $61(10.5)$ & $171(29.3)$ & $54(9.3)$ \\
\hline $\begin{array}{l}\text { 4. For patients with persistent and severe pain, I would increase potent } \\
\text { opioid dosage and administer it q } 4 \text { h, PRN. }\end{array}$ & $51(8.7)$ & $223(38.3)$ & $125(21.4)$ & $116(19.9)$ & $19(3.3)$ \\
\hline $\begin{array}{l}\text { 5. Parenteral administration is more efficacious than oral administration in } \\
\text { chronic pain management. }\end{array}$ & 109 (18.7) & $182(31.2)$ & $52(8.9)$ & $175(30)$ & 27 (4.6) \\
\hline $\begin{array}{l}\text { 6. Oral administration of morphine is more inclined to induce side effects } \\
\text { of nausea and vomiting than parenteral administration }\end{array}$ & $55(9.4)$ & $190(32.6)$ & $132(22.6)$ & 149 (25.6) & $14(2.4)$ \\
\hline $\begin{array}{l}\text { 7. I do not like to prescribe opioids, because respiratory depression is a } \\
\text { very severe side effect. }\end{array}$ & $61(10.5)$ & $180(30.9)$ & 77 (13.2) & $201(34.5)$ & $25(4.3)$ \\
\hline $\begin{array}{l}\text { 8. When prescribing opioids, I would be very careful in the control of } \\
\text { dosage and frequency for the prevention of drug tolerance and addiction. }\end{array}$ & $228(39.1)$ & $264(45.3)$ & 27 (4.6) & $15(2.6)$ & $10(1.7)$ \\
\hline
\end{tabular}

Table V: Logistic Regression Analysis of Various Factors Associated with Knowledge deficits of Opioid Prescribing

\begin{tabular}{|l|c|c|c|c|c|c|c|c|}
\hline & & & & & \multicolumn{2}{c|}{ Odds Ratio } & \multicolumn{2}{|c|}{$95 \%$ C.I. for OR } \\
\cline { 3 - 8 } & & B & S.E. & Wald & df & P & Lower & Upper \\
\hline Yrs in Practice & -.175 & .360 & .235 & 1 & .627 & .840 & .414 & 1.701 \\
\hline Community Size & -.383 & .705 & .295 & 1 & .587 & .682 & .171 & 2.714 \\
\hline No. of Pts seen & -.761 & .495 & 2.358 & 1 & .125 & .467 & .177 & 1.234 \\
\hline Profession & -.168 & .385 & .191 & 1 & .662 & .845 & .398 & 1.797 \\
\hline Opioid Prescription & .316 & .408 & .601 & 1 & .438 & 1.372 & .616 & 3.054 \\
\hline Investigation & 1.252 & .438 & 8.167 & 1 & .004 & 3.497 & 1.482 & 8.254 \\
\hline Late stage patients & -1.013 & .448 & 5.124 & 1 & .024 & .363 & .151 & .873 \\
\hline Practice District & .161 & .399 & .163 & 1 & .686 & 1.175 & .537 & 2.568 \\
\hline Constant & 1.284 & .686 & 3.504 & 1 & .061 & 3.612 & & \\
\hline
\end{tabular}


We evaluated multiple physician characteristics by logistic regression to identify which group of physicians would be inclined to have inadequate knowledge to prescribe opioids. The mean score (2.55) and median score (2.87) were out of a perfect mean score of 5.00. A participant physician was classified having "inadequate knowledge to prescribe opioids" if his/her mean score was equal to or less than 3.00 on the knowledge scale. A binomial variable was derived as the inadequate knowledge versus adequate knowledge to prescribe opioids. This variable was used as the dependent variable in the logistic regression (Table V).

Attitudes toward Opioid Prescribing: The mean (SD) score was 2.40 (0.44, range 1.37-4.09) and the median was 2.37 for this scale. Table 6 contains the specific response frequencies and percentages for each item surveyed. Results demonstrated that physicians attitude towards opioids are of negative in general. Eighty nine percent of the physicians agreed that they were very careful in the control of drug dosage and frequency for the prevention of drug tolerance and addiction while prescribing opioids. Fifty five percent of the physicians would not prescribe opioids due to their belief of respiratory depression being a severe side effect (Table IV).

Fifty six percent of the practicing physicians think that in their hospital most of the patients receive adequate pain treatment. Half of the respondents had an opinion that $80 \%$ of pain can be relieved with pharmacological pain relievers. Among the responding physicians $31 \%$ believe that legitimate prescription of narcotic pain-relieving drugs in cancer patients do not cause addiction. Interestingly, only $7 \%$ had an opinion towards $0.1 \%$, which was the correct answer. Forty five percent of the physicians reported that when a cancer patient requests increasing amounts of analgesic to control pain, this usually indicate that the patient was psychologically addicted, has developed tolerance to the drug as well as experiencing increased pain.

\section{Discussion}

Previous studies revealed that physicians are generally not comfortable using opioid analgesics to treat patients with severe acute or chronic pain. Insufficient knowledge and attitude of health professionals towards opioids and pain has a significant influence in the pain management. Physicians hold many misconceptions about the use and risks associated with the use of opioid analgesics, as well as the policies that govern their use $^{17}$. Physicians are often concerned that their prescribing for legitimate medical purposes can unintentionally contribute to illicit use and create addiction in their patients ${ }^{18}$. Such misperceptions may lead to decreased prescribing and inadequate treatment of pain.

It was notable that $66 \%$ of the physicians had seen cancer patients in the last 12 months and $65 \%$ had seen patients with advanced stage cancer where opioids are considered as the mainstay of treatment. The study results clearly demonstrated that majority of the physicians had a poor knowledge \& attitude towards opioids availability, accessibility and use. Though medical specialty was found to have a profound effect on the knowledge and attitude toward appropriate opioid use in previous studies, our study found that oncology had more impact on knowledge ${ }^{19}$. Our study found that physicians with more years of practice experience had better opioid knowledge and attitudes which was same as another study ${ }^{20}$.

Theory suggests that physicians prescribe by traditional behavior ${ }^{21}$ based on the norms of the community they reside. Community beliefs and attitudes are part of this behavior and customary behavior ignores the outcome of their action. As for example, a physician's reluctant opioid prescription would lead patients to be in severe pain. "Cognitive-behavioral" theory suggests that behavior is mediated by cognition: what people know and think affects how they act. Specific behavior is guided by two factors 1) the attitude towards the act and 2) perceived normative beliefs of reference groups, multiplied by the person's motivation to comply with the group expectations ${ }^{21}$.

We would like to discuss our overall findings in five broad headings: 1. Opioid availability: Opioid availability means a country has stock of approved opioid analgesics at the manufacturer or retail level of the drug distribution system. The preamble of the Single Convention stated "governments have the obligation to ensure opioid availability, recognizing that ...the medical use of narcotic drugs continues to be indispensable for the relief of pain and suffering and that adequate provision must be made to ensure the availability of narcotic drugs for such purposes"(Preamble) ${ }^{22}$.

WHO Guideline emphasizes the absolute importance of physician concentration: Guideline 10 stated that "National drug control authorities and health care professionals should cooperate to ensure the availability of opioid analgesics for medical and scientific purposes, including for the relief of pain" (p.19) 22 .

2. Opioid accessibility: Opioid accessibility refers to the patients' ability to obtain the opioid 
analgesics for pain relief. Access to the drug by patients is not possible unless opioids are available in the country and in the distribution system. Therefore opioids may be legally available within a country or even at health care facilities, but patients may not be able to access them for a variety of reasons, including: Health care professionals' reluctance to prescribe opioids, health professionals' lack of knowledge about how to prescribe opioids, restrictive procedures for prescribing or dispensing opioids or cost of opioid products. Our study revealed that $74 \%$ physicians found 'physicians reluctance' and 59\% thought 'nurses' reluctance' as barriers to access.

3. Bangladesh Narcotics Law, 1990: 'Don't know', 'not a problem' or 'minor problem' was the response of $53 \%$ of the physicians regarding Bangladesh Narcotics Law or regulations that restrict the amounts of opioids which can be prescribed. Interestingly, Bangladesh narcotics law or regulations do not restrict amount or time limit to prescribe opioid for medical use. Ironically, the most important barrier is to restrict level of physician who can prescribe opioid is restricted. More than half of the respondents did not know that in Bangladesh, it is not very difficult to obtain the necessary licenses to prescribe opioids.

Complex and restrictive laws can undermine the dual imperative that governments should establish a system of narcotics control that prevents the misuse of drugs while, at the same time, ensuring their adequate and continuous availability for legitimate medical purposes $^{22}$. This is the principle of balance $^{23}$. DNC website stated that, "The Government of the People's Republic of Bangladesh enacted the 'Narcotics Control Act in 1990 ' repealing all the colonial laws with a view to encountering drug problem true to the aspiration of our society ${ }^{24}$.

Surprisingly most of the participating physicians were not aware about the law. Most respondents (67\%) reported 'no concern' regarding the investigations and $23 \%$ reported that they 'don't know' about any such issue, only $9.8 \%$ had knowledge on about opioids.

4. Opioid Pharmacology: In comparison to other studies more physicians in this study showed significantly inadequate knowledge of basic facts of opioid pharmacology such as choice of potent opioids (morphine or pethidine), schedules (around the clock or PRN) and routes (by oral or parenteral $)^{\mathbf{2 5}}$. More than half of the respondents did not know that parenteral opioid administration is not more efficacious than oral administration in chronic pain management, while almost one-third of the respondents were unsure whether oral administration of morphine is more inclined to induce side effects of nausea and vomiting than parenteral administration. It was discouraging that $85 \%$ of the physicians would prefer pethidine rather than morphine to prescribe when patients need potent opioids for severe acute pain.

Pethidine is a short acting opioid, historically widely available in Bangladesh for managing pain. It is no longer recommended by the World Health Organization for the treatment of chronic pain because of side effects caused by the accumulation of a toxic metabolite. Pethidine causes more vomiting due to antimuscarinic effects. Pethidine has ceiling effect because of toxic metabolite norpethidine which cumulates when pethidine is given regularly and in renal impairment, causing tremors, multifocal myoclonus, agitation and occasionally seizures ${ }^{25}$.

5. Addiction: More physicians (89\%) displayed concern about the rapid development of tolerance and addiction than physicians in other studies ${ }^{13}$. This concern had reflected significantly in their attitude towards opioid prescribing. Furthermore, more physicians (37\%) overestimated the likelihood of addiction (addiction rate $>1 \%$ ) than physicians $(27 \%)$ in another study. Interestingly, $27 \%$ of the physicians in our study chose 'no addiction at all' due to opioid use.

The most commonly perceived barrier by physicians in regards to opioids are physical dependence, tolerance, and addiction ${ }^{20}$. This phenomenon was also evident here. Fifty six percent of the physicians agreed to decrease opioid dosage than the required dosage to avoid drug tolerance and $89 \%$ of the respondents responded to be very careful in the control of dosage and frequency for the prevention of drug tolerance and addiction.

This study had several limitations. First, the response rate was only $58.3 \%$ which may not be generalizable to the whole population. The content validity of the survey instrument was not evaluated for Bangladeshi physicians, but most items were based on previously-published surveys that examined similar issues. Future research should test potentially effective strategies in a well-designed manner.

Conclusion: A physician's clinical knowledge, attitudes and awareness about opioid analgesics help shape their prescribing practices and treatment. Effective opioid knowledge needs to be reliant on the kinds of skills that physicians would feel competent to prescribe opioids. Given the central role of physicians in pain management, it seems to be essential that they are trained explicitly in the undergraduate and postgraduate levels of 
medical education. It is important to enable them to recognize and address risk, good, effective, engaging and balanced opioid use for pain management.

\section{Acknowledgement}

The authors thank the Bangladesh Medical Research Council (BMRC), Government of Bangladesh for providing financial assistance for the study. The authors thankfully acknowledge the contribution of Dr. Martha A. Maurer, PhD, codirector, Pain \& Policy Studies Group, University of Wisconsin Carbone Cancer Center, WHO Collaborating Center for Pain Policy and Palliative Care, Madison, USA and Dr. Suresh Kumar, Director, Institute of Palliative Medicine, WHO collaborating centre for community participation in Palliative Care and Long Term Care, for their help in formulating the study questionnaire.

\section{References}

1. Fallon M, Cherny NI, Hanks G (2010) Opioid analgesic therapy. In: Hanks G, Cherny NI, Christakis NA, Fallon M, Kaasa S, Portenoy RK (eds) Oxford Textbook of Palliative Medicine, 4th edn. Oxford University Press, New York, pp. 661-698.

2. World Health Organization. Cancer Pain Relief: With a Guide to Opioid Availability, 2nd edition. Geneva, Switzerland: World Health Organization; 1996.

3. Kalso E, Edwards JE, Moore A, McQuay H. Opioids in chronic non-cancer pain: Systematic review of efficacy and safety. Pain 2004; 112: 372-80.

4. World Health Organization. The use of essential drugs: report of a WHO Expert Committee (technical report series 882). Geneva: WHO, 1998.

5. VonRoenn JH, Cleeland CS, Gonin R, et al. Physician attitudes and practice in cancer pain management: a survey from the Eastern Cooperative Oncology Group. Ann Intern Med 1993; 119: 121-126.

6. Ger LP, Ho ST, Wang JJ. Physicians' Knowledge and Attitudes Toward the Use of Analgesics for Cancer Pain Management: A Survey of Two Medical Centers in Taiwan. J Pain Symptom Manage 2000; 20: 335344.

7. Bonica J. The management of pain. 2nd ed. Philadelphia (PA): Lea and Febiger; 1990.

8. Wolfert M Z., Gilson A M, Dahl J L., Cleary J F.Opioid Analgesics for Pain Control: Wisconsin Physicians' Knowledge, Beliefs, Attitudes, and Prescribing PracticesPain Medicine 2010; 11: 425-434.

9. Watt-Watson J, Hunter J, Pennefather P, Librach L, Raman-Wilms L, Schreiber M, et al. An integrated undergraduate pain curriculum, based on IASP curricula, for six health science faculties. Pain 2004; 110(1-2): 140-8.

10. Poyhia R, Niemi-Murola L, Kalso E. The outcome of pain related undergraduate teaching in Finnish medical faculties. Pain 2005; 115(3): 234-7.
11. Wells M, Dryden H, Guild P, et al. The knowledge and attitudes of surgical staff towards the use of opioids in cancer pain management: Can the Hospital Palliative Care Team make a difference? Eur J Cancer Care $2001 ; 10: 201-11$.

12. Misbahuddin, M ; Hossain, M S; Iqbal, K M ; Haque, M Z. Medical use of opioids in Bangladesh. The Lancet 2001; 358: 1181-82.

13. Dehghan, R.; Ramakrishnan, J.; Ahmed, N.; Harding, $\mathrm{R}$. The use of morphine to control pain in advanced cancer: an investigation of clinical usage in Bangladesh. Palliative Medicine 2010; Vol. 24(7), pp.707-14.

14. Pain policy studies group. Achieving Balance in State Pain Policy: A Progress Report. www.painpolicy.wisc. edu/sites/www.painpolicy.wisc.edu/.../prc2012.pdf.

15. Morrison R S, M.D., Wallenstein S., Natale D K., Senzel R S, M.R.P.Huang LL. "We don't carry that" Failure of pharmacies in predominantly nonwhite neighborhoods to stock opioid analgesics. N Engl J Med 2000; 342: 1023-1026.

16. Kaasalainen V., Vainio A., Melkkila $\mathrm{T}$ A. Developments in the treatment of cancer pain in Finland: the third nation-wide survey Pain 70 (1997); 175-183.

17. Foley KM. Misconceptions and controversies regarding the use of opioids in cancer pain. Anticancer Drugs 1995; 3: 4-13.

18. Savage SR, Joranson DE, Covington EC, et al Definitions related to the medical use of opioids: Evolution towards universal agreement. J Pain Symptom Manage 2003; 26: 655-67.

19. Mantyselka P, Kumpusalo E, Ahonen R, Kumpusalo A, Kauhanen J, Viinamaki H, et al. Pain as a reason to visit the doctor: a study in Finnish primary health care. Pain 2001; 89: 175-80.

20. Ferrell BR, McGuire DB, Donovan MI. Knowledge and beliefs regarding pain in a sample of nursing faculty. J Prof Nurs 1993; 9: 79-88.

21. Termin P. Taking your medicine: drug regulation in the United States. Cambridge, MA: Harvard University Press 1980: 106-119.

22. World Health Organization. Achieving balance in national opioids control policy: guidelines for assessment. Geveva: WHO, 2000.

23. Department of Narcotic Control Bangladesh. 'Narcotics Control Act 1990 (Amendment 2004)', http//www. dnc.gov.bd/rulsacts.html.

24. Department of Narcotic Control Bangladesh. 'DNC Rules 1999 original', http//www.dnc.gov.bd/ rulsacts.html.

25. Twycross R., Wilcock A. Palliative care formulary. $3^{\text {rd }}$ edition. United Kingdom, Nottingham: palliativedrugs.com Ltd; 2003. 